\title{
Políticas de Saúde Pública, Impostos sobre as bebidas alcoólicas e com açúcar e do tabaco em Portugal
}

https://doi.org/10.21814/uminho.ed.30.7

\author{
Carlos Rodrigues \\ Professor de Direito - Investigador do \\ Instituto Jurídico Portucalense - IJP, Porto
}

\section{Introdução}

O nosso estudo analisa a aplicabilidade do princípio da equivalência, ou os também designados impostos regulatórios ou impostos corretivos, subjacente à criação dos impostos sobre o tabaco, sobre as bebidas alcoólicas e as bebidas adicionadas de açúcar ou outros edulcorantes, com a finalidade de compreendermos a sua dupla função. Arrecadação de receita fiscal e diminuição do consumo destes bens.

\section{A proteção constitucional da saúde}

\subsection{0 direito à proteção à saúde na Constituição da República Portuguesa}

Se atentarmos no artigo $64 .^{\circ}$ da Constituição da República Portuguesa - CRP, estabelece no seu n. ${ }^{\circ} 1$ que todos têm direito à proteção da saúde, contudo também nos diz que a todos é imposto o dever de a defender e promover.

Evidentemente que este direito à proteção da saúde integra duas componentes que se interligam e complementam, ou seja, se por um lado há o direito de exigir ao Estado e a todos os outros que nos rodeiam, isto é, a terceiros, que não pratiquem atos que possam pôr em causa a saúde de cada um de nós, e logicamente a saúde de todos, igualmente estabelece um dever individual e geral de abstenção, o que significa que temos o direito de exigir ao Estado que tome as medidas que concretizem estes direitos através da criação das necessárias prestações que tenham como finalidade prevenir as doenças e proceder ao seu necessário tratamento ${ }^{1}$.

Sobressaem para nós desta realidade constitucional dois factos importantes. Se por um lado cada um de nós tem o dever de promovermos e defendermos a nossa saúde,

1 Veja-se GOMES CANOTILHO, J. J. e VITAL MOREIRA. Constituição da República Portuguesa - Anotada -

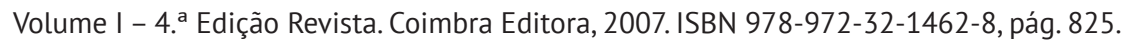


isto como seres humanos individualmente considerados, por outra via temos o dever de promovermos e defendermos a saúde de cada um dos outros, logo a saúde pública². Esta tarefa está a cargo quer de cada concreto ser humano, quer de cada pessoa jurídica que, por ação ou omissão, não o faça no desenvolvimento do seu escopo social.

Curiosamente a CRP na alínea f) do n. 3 deste artigo $64 . .^{\circ}$ impõe que sejam estabelecidas políticas públicas de prevenção e de tratamento da toxicodependência, desde a sua revisão constitucional de 1997, mas nada refere acerca do tabaco, do álcool e do açúcar.

Naquela data o poder constituinte entendeu por bem tentar travar um flagelo nacional, isto é, criar linhas diretrizes constitucionais que dessem guarida ao combate à toxicodependência e que se traduzissem quer na prevenção, quer no tratamento das pessoas afetadas diretamente, quer de todas aquelas que indiretamente o são.

Evidentemente que apesar de o poder constituinte ter valorizado constitucionalmente este problema de saúde pública, de facto não podemos olvidar que nesta mesma linha temos outros problemas de saúde pública motivados pelo tabagismo, consumo de bebidas alcoólicas e de elevados teores de açúcar que se enquadram dentro do âmbito de uma promoção para a educação sanitária do povo e para as práticas de vida saudável que estão incorporadas na alínea b) do $n .^{\circ} 2$ daquele artigo da CRP.

\subsection{O Serviço Nacional de Saúde na Constituição da República Portuguesa}

O direito constitucional da proteção à saúde está a cargo do Estado através da criação do Serviço Nacional de Saúde - SNS e que de acordo com a imposição constitucional tem que ter caráter universal e geral, impondo-se-lhe ainda que seja tendencialmente gratuito.

Evidentemente que a existência do SNS acarreta logicamente que a sua prestação de serviços seja suportada diretamente pelo orçamento do Estado através da socialização dos custos dos cuidados médicos e medicamentos - vide alínea c) do n. 3 do artigo 64. ${ }^{\circ}$ da CRP3 ${ }^{3}$, ou seja, será o Estado através da arrecadação de receitas tributárias que suporta as despesas geradas pelo SNS. É que na realidade vivemos num "Estado Fiscal", isto é, vivemos num Estado em que as receitas obtidas para fazerem face às despesas que em cada ano constam do Orçamento Geral do Estado - OE, proveem, por excelência, da arrecadação de impostos e contribuições, o que significa a gratuidade em geral é suportada por todos através dos seus impostos.

2 GOMES CANOTILHO, J. J. e VITAL MOREIRA, op. cit., p. 826.

3 GOMES CANOTILHO, J. J. e VITAL MOREIRA, op. cit., pp. 827-828. 


\section{Dados estatísticas sobre a saúde}

Neste momento vamos fazer uma breve análise a alguns dados estatísticos para compreendermos quais os efeitos para a saúde individual de cada um, e no conjunto para a saúde pública, de alguns hábitos da população em geral.

\subsection{Evolução das consultas de apoio intensivo à cessação tabágica}

São bem conhecidos os feitos nefastos do tabagismo. Para percecionarmos o total de consultas para apoio à cessação tabágica, extraímos do "Relatório Anual de 2019" para o "Acesso a cuidados de saúde nos estabelecimentos do SNS e entidades convencionadas”, publicado pelo Ministério da Saúde.

$\begin{array}{ccccccccccc} & 2010 & 2011 & 2012 & 2013 & 2014 & 2015 & 2016 & 2017 & 2018 & 2019 \\ \begin{array}{c}\text { Total de } \\ \text { consultas }\end{array} & 19620 & 20667 & 20898 & 22358 & 26043 & 30706 & 31822 & 39763 & 44099 & 41651 \\ \begin{array}{l}\text { Primeiras } \\ \text { consultas }\end{array} & 4917 & 5778 & 6959 & 5631 & 7527 & 8563 & 7134 & 11493 & 12961 & 12578\end{array}$

Ressalta deste relatório anual um aumento de $212,288 \%$ do número total de consultas, entre 2010 e 2019, para se que este vício cesse, sendo essa percentagem ainda maior quando analisamos o acesso à primeira consulta com um aumento de $255,806 \%$.

\subsection{Utentes sob intervenção em Centros de Responsabilidade Integrados com problemas ligados ao álcool}

Os problemas de saúde gerados pelo consumo de bebidas alcoólicas são sobejamente conhecidos e o gráfico infra expressa-nos de forma viva as pessoas que estão em tratamento, ou que $o$ iniciaram, para porem fim a essa maleita. $O$ quadro infra exibe dados extraídos do "Relatório Anual de 2019" para o "Acesso a cuidados de saúde nos estabelecimentos do SNS e entidades convencionadas", publicado pelo Ministério da Saúde ${ }^{6}$.

\footnotetext{
4 Relatório Anual de 2019 para o Acesso a cuidados de saúde nos estabelecimentos do SNS e entidades convencionadas, Ministério da Saúde. [Consultado em 2021/05/15] Disponível em https://www.sns.gov. pt/wp-content/uploads/2020/09/Relatorio_Anual_Acesso_2019.pdf p. 36.

5 Relatório Anual de 2019 para o Acesso a cuidados de saúde nos estabelecimentos do SNS e entidades convencionadas, Ministério da Saúde. [Consultado em 2021/05/15] Disponível em https://www.sns.gov. pt/wp-content/uploads/2020/09/Relatorio_Anual_Acesso_2019.pdf, p. 133.

6 Relatório Anual de 2019 para o Acesso a cuidados de saúde nos estabelecimentos do SNS e entidades convencionadas, Ministério da Saúde. [Consultado em 2021/05/15] Disponível em https://www.sns.gov. pt/wp-content/uploads/2020/09/Relatorio_Anual_Acesso_2019.pdf, p.18.

\section{Ouadro 1}

Consultas cessação tabágica. 
Quadro 2

Tratamento de alcoolismo.

\section{Quadro 3}

Percentagem de pré-obesos entre os inscritos no SNS.

\section{Quadro 4}

Percentagem de obesos entre os inscritos no SNS.

$\begin{array}{ccccccccccc} & 2010 & 2011 & 2012 & 2013 & 2014 & 2015 & 2016 & 2017 & 2018 & 2019 \\ \begin{array}{c}\text { Utentes em } \\ \text { tratamento } \\ \text { no ano }\end{array} & 10382 & 10848 & 11117 & 11616 & 11881 & 12498 & 13678 & 13828 & 13422 & 13951 \\ \quad \begin{array}{c}\text { Novos } \\ \text { utentes }\end{array} & 1549 & 3009 & 3344 & 3403 & 3353 & 3704 & 3759 & 3352 & 3403 & 3416\end{array}$

Este relatório demonstra o aumento constante de pessoas que recorrem às consultas, quer já em tratamento, quer no acesso a ele.

\subsection{A pré-obesidade e a obesidade em Portugal e as implicações no SNS}

De acordo com o "programa nacional para a promoção da alimentação saudável 2020", a obesidade afeta cerca de $22 \%$ da população nacional, o que provoca uma pressão constante no Serviço Nacional de Saúde.

De acordo com esse estudo, e tendo em atenção o número de utentes do SNS, tem havido um aumento constante de utentes inscritos nos Cuidados de Saúde Primários com registo de pré-obesidade. 0 quadro infra regista a evolução gradativa da percentagem entre o total de utentes inscritos no SNS e aqueles que apresentam sinais de pré-obesidade em Portugal Continental.

$\begin{array}{ccccccc}\text { ANO } & 2014 & 2015 & 2016 & 2017 & 2018 & 2019 \\ \% & 4,8 \% & 5,8 \% & 6,4 \% & 7,0 \% & 12,9 \% & 16,7 \%\end{array}$

Se atentarmos naquele estudo e observamos os dados relativos à obesidade, a evolução entre total de utentes inscritos nos Cuidados de Saúde Primários e aqueles que apresentam sinais de obesidade em Portugal Continental é 7 .

$\begin{array}{ccccccc}\text { ANO } & 2014 & 2015 & 2016 & 2017 & 2018 & 2019 \\ \% & 6,0 \% & 7,7 \% & 8,0 \% & 8,6 \% & 10,7 \% & 11,9 \%\end{array}$

Os dados expostos mostram-nos a flagelo da obesidade na saúde pública nacional.

\section{A tributação como elemento influenciador na proteção da saúde pública}

Em 1920 o economista Arthur Pigou na sua obra "The Economics of Welfare"8 demonstrou que a criação de um tributo sobre determinados produtos que geram efeitos colaterais negativos para a sociedade levam a uma diminuição do seu consumo e, por via desse facto, provocam as necessárias correções na diminuição do seu consumo e também contribuem para cobrir os custos sociais desses efeitos negativos

7 Relatório Anual de 2019 para o Acesso a cuidados de saúde nos estabelecimentos do SNS e entidades convencionadas, Ministério da Saúde. [Consultado em 2021/05/15] Disponível em https://www.sns.gov. pt/wp-content/uploads/2020/09/Relatorio_Anual_Acesso_2019.pdf, p. 18.

8 PIGOU A. C. - The Economics of Welfare. Publisher Macmillan and Co.: London, 1920. 
na sociedade. Hoje em dia está bem patente esse facto na tributação criada por exemplo no âmbito da poluição ambiental, no tabaco, nas bebidas alcoólicas e nas bebidas com açúcar.

Chegados aqui vamos, então, fazer uma breve análise ao sistema tributário português para compreendermos como é que se interligam alguns impostos com a proteção da saúde pública.

\subsection{O Sistema Tributário na Constituição da República Portuguesa}

O n. ${ }^{\circ} 1$ do artigo $103 . .^{\circ}$ da CRP estabelece que o sistema fiscal tem como finalidade a satisfação das necessidades do Estado e também uma repartição justa dos rendimentos e da riqueza. A sua interligação com o seu n. ${ }^{\circ} 4$ do artigo $104 .^{\circ}$ ressalta que a tributação do consumo tem que se adaptar à evolução das necessidades do desenvolvimento económico e da justiça social, justiça social esta que faz parte do leque das incumbências prioritárias do Estado enunciada no artigo 81. ${ }^{\circ}$ da CRP e que na sua alínea b) impõe ao Estado que a promoção dessa justiça social seja assegurada através do sistema fiscal'?

Como sistema que é, tem que comportar em si uma coerência interna, mas também externa com todas as outras funções do Estado Socia ${ }^{10}$. É que não nos podemos esquecer que a finalidade principal da arrecadação dos impostos é para o Estado e outras entidades públicas fazerem face às suas despesas ${ }^{11}$. Evidentemente que esta ligação tem um elo fundamental e funcional com as outras funções do Estado, designadamente com as necessidades financeiras do Sistema Nacional de Saúde na sua função de Estado Social ${ }^{12}$.

\subsection{Os Impostos especiais de Consumo}

O Decreto-Lei n. ${ }^{\circ} 73 / 2010$, de 21 de junho, aprovou o Código dos Impostos especais de Consumo que integram na sua parte especial, e para o que aqui nos interessa, o "Imposto sobre as bebidas alcoólicas", o "Imposto sobre Bebidas não alcoólicas" e o "Imposto sobre o Tabaco".

O preâmbulo daquele diploma tem o cuidado de chamar à atenção para o facto destes tributos terem uma ligação especial com os custos da saúde pública ao escrever taxativamente que também se tinha aproveitado para contemplar no texto normativo,

9 Veja-se GOMES CANOTILHO, J. J. e VITAL MOREIRA Constituição da República Portuguesa - Anotada Volume I - 4. ${ }^{a}$ Edição Revista. Coimbra Editora, 2007. ISBN 978-972-32-1462-8, págs. 968, 1088 e 1089 , 1101.

10 Veja-se MALVÁREZ PASCUAL, Luis Alberto - La función tributaria en el marco del Estado social y democrático de derecho in Derecho Financiero Constitucional. "Estudios en Memoria del Profesor Jaime García Añoveros" Civitas: España, 2001.

11 Veja-se CASALTA NABAIS, José - Direito Fiscal. 11. a Edição. Almedina: Coimbra, 2007.

12 Veja-se CASALTA NABAIS, José - Direito Fiscal. 11. a Edição. Almedina: Coimbra, 2007. 
enquanto princípio legitimador destes impostos, o princípio da equivalência, distinto do da capacidade contributiva, e que dita a respectiva adequação ao custo provocado pelos contribuintes nos domínios da saúde pública.

É, assim, bem patente a ligação destes tributos com o Estado Social na sua vertente de interligação da obtenção da receita com a tentativa de diminuição do consumo ao provocar um aumento do preço de venda ao público, por um lado, mas também obter receitas para fazer face às despesas da saúde pública geradas pelas doenças provocadas com o consumo daquele tipo de bens ${ }^{13}$.

Chegados aqui vamos então compreender quais os fluxos financeiros gerados por estes Impostos Especiais, para compreendermos quer o custo que os mesmos representam para o consumidor final aquando da compra dos produtos que onerados com eles, quer a receita que geram para os cofres do Estado ${ }^{14}$.

\subsubsection{Imposto sobre o Tabaco}

O Código dos Impostos Especiais de Consumo - CIEC disciplina entre os artigos 101. e $115 .^{\circ}$ a tributação do "Imposto sobre o tabaco".

De acordo com os dados estatísticos insertos no site da Autoridade Tributária e Aduaneira, este imposto rendeu aos cofres do Estado, entre os anos de 2010 e 2019, um valor que varia entre 1 212,8 milhões de Euros, no ano de 2015 e 1 515,1 milões de Euros no ano de 2016, embora se mantenha de uma forma algo constante na ordem de 1400 milhões de Euros de receita anual.

\section{Quadro 5}

Receita cobrada com o Imposto sobre o Tabaco.

$\begin{array}{cccccc}\begin{array}{c}\text { Ano/Milhões de } \\ \text { Euro }\end{array} & \text { Cigarros } & \begin{array}{c}\text { Charutos e } \\ \text { cigarrilhas }\end{array} & \begin{array}{c}\text { Tabaco de } \\ \text { corte fino }\end{array} & \text { Outros tabacos } & \text { Total } \\ 2010 & 1395,6 & 3,6 & 28,6 & 0,9 & 1428,7 \\ 2011 & 1366,7 & 5,1 & 72,6 & 2,3 & 1446,7 \\ 2012 & 1225,6 & 4,0 & 112,6 & 11,3 & 1353,5 \\ 2013 & 1193,3 & 6,1 & 103,2 & 10,3 & 1312,9 \\ 2014 & 1250,0 & 13,9 & 135,5 & 0,8 & 1400,2 \\ 2015 & 1396,8 & 19,3 & 95,7 & 1,0 & 1212,8 \\ 2016 & 1386,2 & 19,7 & 107,1 & 2,1 & 1515,1 \\ 2017 & 1333,3 & 13,5 & 91,8 & 6,3 & 1444,9 \\ 2018 & 1263,3 & 26,6 & 68,6 & 17,1 & 1375,6 \\ 2019 & 1297,2 & 19,4 & 70,2 & 40,6 & 1427,4\end{array}$

13 Veja-se MACHADO, Jónatas e NOGUEIRA DA COSTA, Paulo - Manual de Direito Fiscal, perspetiva multinível. 3. ${ }^{a}$ edição. Almedina: Coimbra, 2019.

14 Os dados estatísticos que vamos referenciar foram extraídos do site da Autoridade Tributária e Aduaneira, consultado em 2021/05/15, sob a designação "Estatísticas -Receitas cobradas (2010 a 2019)" na página da Web https://info-aduaneiro.portaldasfinancas.gov.pt/pt/estatisticas/Pages/estatisticas.aspx 


\subsection{Imposto sobre o álcool, as bebidas alcoólicas e as bebidas adicionadas de açúcar ou outros edulcorantes}

O CIEC integra originariamente normas que disciplinam a tributação das bebidas alcoólicas. Desde a sua modificação pela Lei n. ${ }^{\circ}$ 52/2016, de 28 de Dezembro, Lei do Orçamento de Estado para o ano de 2017, que passou a integrar regras disciplinadoras da tributação das bebidas adicionadas de açúcar ou outros edulcorantes.

$\begin{array}{lllllllllll}\text { Ano } & 2010 & 2011 & 2012 & 2013 & 2014 & 2015 & 2016 & 2017 & 2018 & 2019 \\ \begin{array}{c}\text { Receita } \\ \text { em }\end{array} & & & & & & & & & & \\ \begin{array}{c}\text { Milhões de } \\ \text { Euro }\end{array} & 182,0 & 172,8 & 168,0 & 173,1 & 176,1 & 182,9 & 193,6 & 279,4 & 290,9 & 279,4 \\ & & & & & & & & & & \end{array}$

A receita fiscal arrecada com estes impostos nos anos de 2017, 2018 e 2019, depois de ter entrado em vigor a tributação das comparativamente "bebidas adicionadas de açúcar ou outros edulcorantes", comparativamente com o ano de 2016, teve um acrescimento de $152,761 \%$ par a 2017, de $159,048 \%$ para 2018 e de 152,761\% para 2019, ou seja, a tributação deste tipo de bebidas provocou um aumento de receita em mais de 50\% naqueles anos, comparativamente com o cobrado no ano de 2016.

Tendo em atenção os dados divulgados pelo "Programa Nacional para a Promoção da Alimentação Saudável - 2020", o volume de vendas das bebidas açucaradas, entre os anos de 2017-2020 sofreu uma diminuição de cerca de $15 \%$, ou seja, a tributação provocou uma diminuição do consumo deste tipo de bebidas e um aumento significativo de receita fiscal ${ }^{15}$.

\section{Conclusão}

Evidencia este tipo concreto de tributação dos impostos especiais sobre o consumo que o poder político-legislativo o utiliza para criar impostos regulatórios influenciadores da desincentivação do consumo de produtos nocivos à saúde pública. A utilização do princípio da equivalência no sistema fiscal onera os contribuintes que através de efeitos nefastos para a saúde pública provocam custos financeiros para a manutenção do Estado Social. Estamos assim perante impostos com funções corretivos ou extrafiscais.

15 Veja-se o Programa Nacional para a Promoção da Alimentação Saudável - 2020. [consultado em 2021/05/15]Disponível na internet em https://alimentacaosaudavel.dgs.pt/activeapp2020/wp-content/ uploads/2020/11/Relato\%CC\%81rio-PNPAS-2020.pdf pág. 37. 
Estatísticas - Receitas cobradas (2010 a 2019). Autoridade Tributária e Aduaneira. [consultado em 2021/05/15] disponível na internet em https://info-aduaneiro.portaldasfinancas.gov.pt/pt/estatisticas/ Pages/estatisticas.aspx.

CASALTA NABAIS, José - Direito Fiscal. 11. ${ }^{a}$ Edição. Almedina: Coimbra, 2007.

GOMES CANOTILHO, J. J. e VITAL MOREIRA - Constituição da República Portuguesa - Anotada - Volume I 4. ${ }^{a}$ Edição Revista. Coimbra Editora, 2007. ISBN 978-972-32-1462-8, pág. 825.

MACHADO, Jónatas e NOGUEIRA DA COSTA, Paulo - Manual de Direito Fiscal, perspetiva multinível. 3. ${ }^{a}$ edição. Almedina: Coimbra, 2019.

MALVÁREZ PASCUAL, Luis Alberto - La función tributaria en el marco del Estado social y democrático de derecho in Derecho Financiero Constitucional. "Estudios en Memoria del Profesor Jaime García Añoveros" Civitas: España, 2001.

PIGOU A. C. - The Economics of Welfare. Publisher Macmillan and Co.: London, 1920.

Programa Nacional para a Promoção da Alimentação Saudável - 2020. [consultado em 2021/05/15]Disponível na internet em https://alimentacaosaudavel.dgs.pt/activeapp2020/wp-content/uploads/2020/11/ Relato\%CC\%81rio-PNPAS-2020.pdf. pág. 37.

Relatório Anual de 2019 para o Acesso a cuidados de saúde nos estabelecimentos do SNS e entidades convencionadas, Ministério da Saúde. [Consultado em 2021/05/15] Disponível em https://www.sns.gov.pt/ wp-content/uploads/2020/09/Relatorio_Anual_Acesso_2019.pdf 